\title{
Perfil microbiológico do biofilme no tubo orotraqueal dos pacientes extubados:
}

\section{Revisão da literatura}

\author{
Microbiological profile of biofilm in the orotracheal tube of extubated patients: Literature review \\ Perfil microbiológico de la biopelícula en el tubo orotraqueal de pacientes extubados: Revisión de la
}

\section{literatura}

Recebido: 05/04/2021 | Revisado: 12/04/2021 | Aceito: 15/06/2021 | Publicado: 29/06/2021

\author{
Antonio Carlos Gargioni Filho \\ ORCID: https://orcid.org/0000-0002-6449-5976 \\ Faculdade FAIPE, Brasil \\ E-mail: tonygargioni@hotmail.com \\ Gisele Lago Martinez \\ ORCID: https://orcid.org/0000-0002-9503-2261 \\ Universidade Federal do Rio de Janeiro, Brasil \\ E-mail: giselelago@gmail.com \\ Alberto Bicudo Salomão \\ ORCID: https://orcid.org/0000-0003-3284-5721 \\ Faculdade FAIPE, Brasil \\ E-mail: albertobsalomao@gmail.com \\ Melissa Guimarães Crepaldi \\ ORCID: https://orcid.org/0000-0002-2664-1426 \\ Faculdade FAIPE, Brasil \\ E-mail: melissagcrepaldi@hotmail.com \\ Luiz Eduardo Alessio Junior \\ ORCID: https://orcid.org/0000-0001-6226-3787 \\ Faculdade FAIPE, Brasil \\ E-mail: lui.alessio@gmail.com \\ Leonardo Henrique Vadenal Panza \\ ORCID: https://orcid.org/0000-0002-6645-3067 \\ Faculdade FAIPE, Brasil \\ E-mail: leonardo.panza@uol.com.br \\ Rachelle Simões Reis \\ ORCID: https://orcid.org/0000-0001-9966-5763 \\ Faculdade FAIPE, Brasil \\ E-mail: rachelle.reis@gmail.com \\ Karina Maria Salvatore Freitas \\ ORCID: https://orcid.org/0000-0001-9145-6334 \\ Centro Universitário Ingá Uningá, Brasil \\ E-mail: kmsf@uol.com.br \\ Marcus Vinicius Crepaldi \\ ORCID: https://orcid.org/0000-0001-7665-0585 \\ Faculdade FAIPE, Brasil \\ E-mail: marcuscrepaldi@yahoo.com.br
}

\begin{abstract}
Resumo
O biofilme oral de paciente hospitalizado, colonizado também por patógenos respiratórios capazes de causar infecção pulmonar, associado a uma pobre higienização pode contaminar o tubo orotraqueal, aumentando o risco de desenvolvimento de pneumonia associada à ventilação mecânica (PAV) em pacientes críticos. O objetivo deste trabalho foi revisar a literatura que apresente o perfil microbiológico do biofilme oral no tubo orotraqueal de pacientes extubados internados em leito de Unidade de Terapia Intensiva (UTI). Dessa forma, buscou-se investigar a presença de patógenos respiratórios na cavidade oral de pacientes em UTI e dados sobre a participação da condição oral no estabelecimento da PAV. Para delinear o estudo, usou-se o critério PICO para realização de revisão sistemática. Dos 72 artigos encontrados, foram selecionados 5 que melhor atendiam ao perfil de elegibilidade, em especial os que traziam melhores índices de confiança, força, consistência e os que traziam os menores índices de erro. Os estudos apresentaram resultados para o perfil microbiológico do tubo endotraqueal que é colonizado por microrganismos orais, principalmente por Streptococcus spp. A maturação desse biofilme impulsionou uma sinergia desses com bactérias mais virulentas, principalmente de Staphylococcus aureus, Pseudomonas aeruginosa, capazes de promoverem PAV. Concluiu-se que o perfil microbiológico do biofilme oral no tubo orotraqueal de pacientes extubados internados em leito de UTI é de bactérias orais, sugerindo a necessidade da manutenção de higienização
\end{abstract}


oral durante a ventilação mecânica para reduzir o reservatório de patógenos respiratórios dentro do biofilme dentário e consequentemente do tubo endotraqueal.

Palavras-chave: Respiração artificial; Bactérias orais; Biofilmes; Placa dental; Perfil microbiológico; Pneumonia aspirativa.

\begin{abstract}
Inpatient oral biofilm, also colonized by respiratory pathogens capable of causing lung infection, associated with poor cleaning may contaminate the orotracheal tube, increasing the risk of developing ventilator-associated pneumonia (VAP) in critically ill patients. The aim of this study was to review the literature that presents the microbiological profile of oral biofilm in the orotracheal tube of extubated patients admitted to Intensive Care Unit (ICU). Thus, we sought to investigate the presence of respiratory pathogens in the oral cavity of patients in ICU and data on the participation of oral condition in the establishment of VAP. In order to delineate the study, the PICO criteria were used to perform a systematic review. Of the 72 articles found, 5 were selected that best met the eligibility profile, especially those that would provide better confidence, strength, consistency and those with the lowest error rates. The studies presented results for the microbiological profile of the endotracheal tube that is colonized by oral microorganisms, mainly by Streptococcus spp. The maturation of this biofilm promoted a synergy of these with more virulent bacteria, mainly of Staphylococcus aureus, Pseudomonas aeruginosa, capable of promoting VAP. It was concluded that the microbiological profile of the oral biofilm in the orotracheal tube of extubated patients admitted to ICU is oral bacteria, suggesting the necessity of maintenance of oral hygiene during mechanical ventilation to reduce the reservoir of respiratory pathogens within the dental biofilm and consequently in the endotracheal tube.
\end{abstract}

Keywords: Artificial respiration; Oral bacteria; Biofilms; Dental plaque; Pneumonia aspiration.

\title{
Resumen
}

La biopelícula oral de un paciente hospitalizado, también colonizada por patógenos respiratorios capaces de causar infección pulmonar, asociada a una mala higiene, puede contaminar el tubo orotraqueal, aumentando el riesgo de desarrollar neumonía asociada al ventilador (NAV) en pacientes críticamente enfermos. El objetivo de este trabajo fue revisar la literatura que presenta el perfil microbiológico de la biopelícula oral en el tubo orotraqueal de pacientes extubados ingresados en una cama de Unidad de Cuidados Intensivos (UCI). Así, se buscó investigar la presencia de patógenos respiratorios en la cavidad bucal de los pacientes en la UCI y datos sobre la participación de la condición bucal en el establecimiento de NAV. Para delinear el estudio, se utilizó el criterio PICO para realizar una revisión sistemática. De los 72 artículos encontrados, se seleccionaron 5 que mejor cumplían con el perfil de elegibilidad, especialmente aquellos con mayor confianza, solidez, consistencia y aquellos con menores tasas de error. Los estudios arrojaron resultados para el perfil microbiológico del tubo endotraqueal colonizado por microorganismos orales, principalmente por Streptococcus spp. La maduración de esta biopelícula condujo a una sinergia de estas con bacterias más virulentas, principalmente Staphylococcus aureus, Pseudomonas aeruginosa, capaces de promover la NAV. Se concluyó que el perfil microbiológico de la biopelícula oral en el tubo orotraqueal de pacientes extubados hospitalizados en una cama de UCI es de bacterias orales, sugiriendo la necesidad de mantener la higiene bucal durante la ventilación mecánica para reducir el reservorio de patógenos respiratorios dentro de la biopelícula dental y en consecuencia del tubo endotraqueal.

Palabras clave: Respiración artificial; Bacterias bucales; Biopelículas; Placa dental; Perfil microbiológico; Neumonía por aspiración.

\section{Introdução}

A boca possui aproximadamente 688 espécies bacterianas (Ass et al., 2005), parte da microbiota oral pode estar associada a complicações infecciosas próprias da cavidade oral e também à distância, podendo apresentar repercussão sistêmica (Safdar, Crnich \& Madi, 2005). Estudos sugerem que espécies bacterianas orais podem estar relacionadas à pneumonia associada à ventilação (PAV) (Dewhrst et al., 2010).

A cavidade oral sofre contínua colonização de microrganismos que se acumulam sobre superfícies descamativas ou sobre superfícies duras como dentes e próteses, podendo formar, nesses casos, acúmulo de biofilme, chamado de placa bacteriana. Inicialmente, a microflora oral contém principalmente bactérias gram-positivas (Streptococcus spp. e Actinomyces spp.) que, em pacientes internados em ambiente hospitalar e principalmente sob ventilação mecânica, gradualmente são substituídas por uma microbiota mais patogênica (p.ex.: Staphylococcus aureus, Pseudomonas aeruginosa e Sreptococcus pneumoniae) potencialmente causadora de infecções respiratórias (Sands et al., 2017). Essa mudança normalmente acontece nas primeiras 48 horas de admissão em unidades de terapia intensiva (UTI) e pode estar relacionada à higienização oral 
inadequada, juntamente com a diminuição dos mecanismos de defesa da saliva, a redução de seu fluxo e a diminuição do princípio de autolimpeza que ocorre durante a mastigação (Barros et al, 2021).

A tudo isso soma-se o fato de que o tubo endotraqueal, que inclusive se torna colonizado por biofilme em seu lúmen interno, mantém a glote aberta facilitando o acúmulo de secreções, fazendo este indivíduo ser considerado crítico por aumentar o risco de aspiração deste conteúdo. A PAV é classificada como uma pneumonia nosocomial, aquela adquirida no ambiente hospitalar, que ocorre após 48 horas do inicio do uso de cânula endotraqueal e ventilação mecânica nos pacientes de UTI. Pode ser responsável por altos índices de morbidade e mortalidade nestes ambientes. Pode atingir $9 \%$ a $40 \%$ do total das infecções adquiridas dentro do ambiente hospitalar e demonstra mortalidade de até 25\% dos casos (Beraldo \& Andrade, 2008).

A etiologia da PAV pode ser considerada multifatorial, tendo a necessidade de ventilação mecânica, aspiração de bactérias que colonizam a cavidade bucal, traumas, depressão do nível de consciência, manipulação oral do paciente - uso de sondas para macro e micro aspiração das secreções traqueobrônquicas e posicionamento do paciente no leito (Ramirez, Ferrer \& Torres, 2007). Estudos recentes demonstram evidência de que a adequação da higienização oral promove uma redução nos níveis bacterianos totais e, consequentemente, reduz o risco de desenvolvimento de PAV (Par, Badovinac \& Plancak, 2014).

Problemas bucais, especialmente a doença periodontal, podem atuar como foco de disseminação de microrganismos patogênicos com efeito sistêmico. Estudos do perfil microbiológico do biofilme no tubo orotraqueal tornará mais clara a importância de relacionar as doenças periodontais com doenças secundárias como a PAV e assim, delinear um protocolo rigoroso de higienização e de descontaminação bucal ao paciente intubado, de preferência realizado e/ou monitorado por um profissional da Odontologia.

\section{Objetivos}

Revisar a literatura que apresente o perfil microbiológico do biofilme oral no tubo orotraqueal de pacientes extubados internados em leito de UTI. Dessa forma, investigar a presença de patógenos respiratórios na cavidade oral em pacientes em UTI e buscar dados sobre a participação da condição oral no estabelecimento da PAV.

\section{Metodologia}

Para delinear a linha de raciocínio do trabalho foi utilizado o critério PICO, sendo População - pacientes extubados internados em ambiente de UTI hospitalar, Intervenção - Análise qualitativa do biofilme orotraqueal extubado, Comparação protocolo de higienização oral mais eficiente diminuiria o risco de desenvolvimento de bactérias patogênicas bucais no biofilme do tubo e Resultado - analisar a prevalência da população de microrganismos restritos à cavidade oral que estavam presentes no biofilme do tubo.

Foi realizada uma Revisão de Literatura que seguiu a investigação qualitativa de patógenos orais mais prevalentes no tubo orotraqueal de pacientes extubados que estão sob cuidados intensivos nas unidades hospitalares de UTI.

Dentre os critérios de elegibilidade, os de inclusão foram:

1) Artigos de pesquisa clínica randomizados (RCT), caso-controle, revisão sistemática ou metanálise,

2) Artigos disponíveis na língua inglesa ou portuguesa,

3) Artigos publicados em revistas indexadas, com publicação a partir de 2007,

4) Pacientes acima de 18 anos de idade,

5) Ambos os gêneros.

Os critérios de exclusão foram: 
1) Artigos com outros temas que pudessem trazer algum viés de confusão ou que não se adequassem dentro das palavras-chaves sugeridas,

2) Pacientes admitidos em leito de UTI já apresentando Pneumonia (pacientes colonizados).

Foram utilizadas buscas nas bases de dados na área da saúde, com acesso via internet, no PubMed e Cochrane, utilizando as seguintes palavras-chaves: "respiração artificial", "respiration, artificial"; "pneumonia aspirativa", "pneumonia, aspiration"; "placa dental", "dental plaque"; "biofilmes", "biofilms". E o método de seleção foi por meio da leitura criteriosa do título e do resumo de cada artigo a fim de definir aqueles que melhor se adequassem a este trabalho. Após, foram lidos os artigos em sua íntegra, observando critérios de elegibilidade e algum dado insuficiente. Artigos com resultados iguais publicados pelo mesmo autor em mais de um periódico, foi incluído apenas uma vez neste trabalho.

\section{Resultados}

Foram localizados 72 artigos publicados em bancos de dados Cochrane (5 artigos) e Pubmed (67 artigos), utilizando os seguintes descritores: "respiração artificial", "mechanical ventilation"; "pneumonia aspirativa”, "aspirative pneumonia"; "placa dental", "dental plaque"; "biofilmes", "biofilms". Deste total, 7 eram artigos duplicados, o que foram descartados e mantidos apenas um exemplar. Vinte e três foram eliminados após leitura do título e outros 5 após a leitura do resumo. Deste total, vinte e cinco foram eliminados de forma a respeitar os critérios estabelecidos de elegibilidade (critérios de exclusão), mantendo, desta forma, 5 artigos para serem considerados para análise na íntegra desta revisão da literatura (Figura 1).

Os cinco artigos utilizados foram publicados em intervalos de 2007 a 2017, onde um deles foi uma revisão de literatura e os demais, desenhos de caso-controle ou transversais. Um dos trabalhos (Perkins, Woeltje \& Angenent, 2010) contou com uma amostra pequena $(n=8)$, o que poderia ser considerado baixo, porém, o estudo expressa fatores de confiança e de consistência altos e revela a necessidade de outros estudos. Os demais estudos apresentaram número de amostras considerados suficientes, índices de confiança, força e consistência adequados. Analisando o risco de viés, este não foi apontado em nenhuma das análises feitas em algum dos artigos (Quadro 1).

Resultado dos estudos (Quadro 2) demonstram que apesar de não ter uma relação causa-efeito ainda estabelecida entre os microorganismos encontrados no tubo endotraqueal e a incidência e agravo de infecção pulmonar (Ramirez, Ferrer \& Torres, 2007), a maior parte das bactérias prevalentes após 23 dias de intubação foi de Pseudomonas aeruginosa (Perkins, Woeltje \& Angenent, 2010) e Streptococcus aureus (Sands et al., 2017), microorganismos de vias aéreas superiores que estão diretamente associadas às pneumonias. Outro trabalho (Cairns et al., 2011) demonstrou que quase metade dos pacientes internados apresentaram presença de Streptococcus mutans, Porphyromonas gingivalis e a Candida albicans no tubo orotraqueal, microorganismos do biofilme dental que podem apresentar alto risco ao desenvolvimento de PAV (Sands et al., 2017), similar atrás evidências que registraram correlação positiva entre Actinomyces actinomycetemcomitans, Porphyromonas gingivalis, e Tannerella Forsythia e o biofilme do tubo em paciente edêntulos (Porto et al., 2016). 
Research, Society and Development, v. 10, n. 7, e45010714661, 2021

(CC BY 4.0) | ISSN 2525-3409 | DOI: http://dx.doi.org/10.33448/rsd-v10i7.14661

Figura 1 - Diagrama demonstrando o processo de seleção dos artigos para a Descrição do Estudo.

\section{RESULTADOS DA REVISÃo SISTEMÁTICA}

1. Descriçẫo do estudo

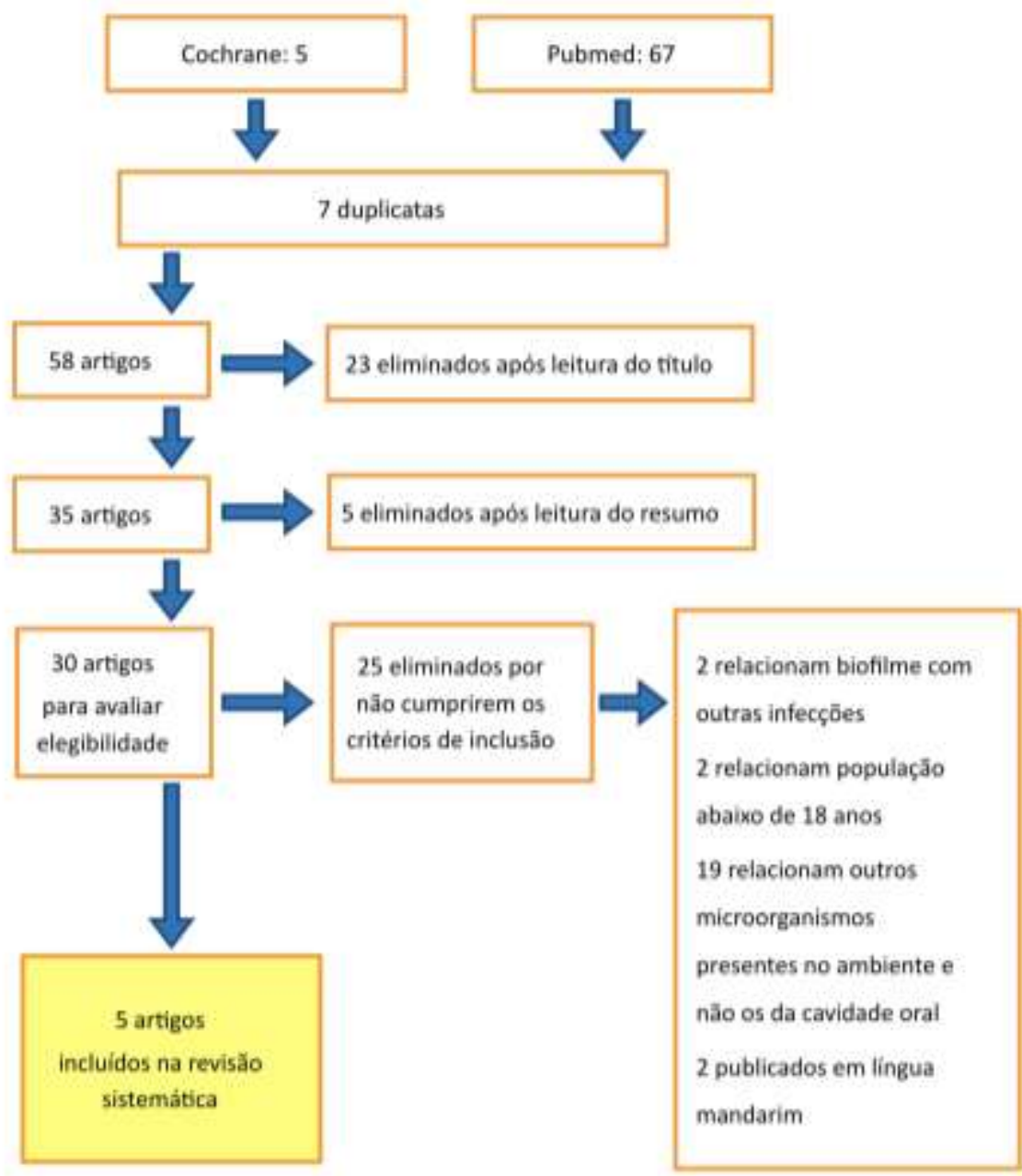

Fonte: Autores. 
Quadro 1 - Risco de viés nos artigos analisados.

\begin{tabular}{|c|c|c|c|c|c|}
\hline Referência & Randomização & $\begin{array}{c}\text { Avaliador } \\
\text { cegado }\end{array}$ & $\begin{array}{l}\text { Resultados } \\
\text { incompletos }\end{array}$ & $\begin{array}{c}\text { Resultados } \\
\text { seletivos }\end{array}$ & $\begin{array}{c}\text { Intenção de } \\
\text { tratar }\end{array}$ \\
\hline $\begin{array}{l}\text { Ramirez, } \\
\text { Ferrer \& } \\
\text { Torres, } 2007\end{array}$ & & & & & \\
\hline $\begin{array}{l}\text { Perkins, } \\
\text { Woeltje \& } \\
\text { Angenent, } \\
2010\end{array}$ & & & & & \\
\hline \multicolumn{6}{|l|}{$\begin{array}{l}\text { Cairns et al., } \\
2011\end{array}$} \\
\hline \multicolumn{6}{|l|}{$\begin{array}{l}\text { Porto et al., } \\
2016\end{array}$} \\
\hline \multicolumn{6}{|l|}{$\begin{array}{l}\text { Sands et al., } \\
2017\end{array}$} \\
\hline Baix & risco de viés & & são claro & & iés claro \\
\hline
\end{tabular}

Fonte: Autores. 
Quadro 2 - Resultado dos estudos (PCR - Reação em Cadeia da Polimerase; DGCE - Diversidade Bacteriana Inter-paciente; ICU - Unidade de Terapia Intensiva; PAV - Pneumonia Associada a Ventilação).

\begin{tabular}{|c|c|c|c|c|c|c|c|}
\hline $\begin{array}{c}\text { Referênci } \\
\text { a } \\
\end{array}$ & $\begin{array}{c}\text { Publica } \\
\text { ção }\end{array}$ & Título & $\begin{array}{l}\begin{array}{l}\text { Tipo de } \\
\text { estudo }\end{array} \\
\end{array}$ & N. & $\begin{array}{c}\text { Evento/Intervençõe } \\
\text { s }\end{array}$ & Desfecho & Viés \\
\hline $\begin{array}{l}\text { Ramirez, } \\
\text { Ferrer \& } \\
\text { Torres, } \\
2007\end{array}$ & $\begin{array}{l}\text { Curr } \\
\text { Opin } \\
\text { Infect } \\
\text { Dis }\end{array}$ & $\begin{array}{l}\text { Prevention } \\
\text { measures for } \\
\text { ventilator- } \\
\text { associated } \\
\text { pneumonia: a } \\
\text { new focus on } \\
\text { the } \\
\text { endotracheal } \\
\text { tube }\end{array}$ & $\begin{array}{l}\text { Revisão } \\
\text { de } \\
\text { Literatura }\end{array}$ & & 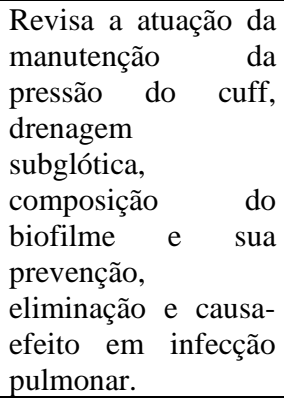 & $\begin{array}{lr}\text { O biofilme funciona } \\
\text { muito mais como } \\
\text { reservatório r de } \\
\text { bactérias, em especial } \\
\text { as Pseudomonas spp. e } \\
\text { Enterobacteriaceae do } \\
\text { que causa-efeito das } \\
\text { bactérias do biofilme } \\
\text { em infecções } \\
\text { pulmonares. }\end{array}$ & \\
\hline $\begin{array}{l}\text { Perkins, } \\
\text { Woeltje } \\
\text { \& } \\
\text { Angenent } \\
, 2010\end{array}$ & $\begin{array}{l}\text { Int J } \\
\text { Med } \\
\text { Microbi } \\
\text { ol }\end{array}$ & $\begin{array}{l}\text { Endotracheal } \\
\text { tube biofilm } \\
\text { inoculation of } \\
\text { oral flora and } \\
\text { subsequente } \\
\text { colonization } \\
\text { of } \\
\text { opportunistic } \\
\text { pathogens }\end{array}$ & $\begin{array}{l}\text { Transvers } \\
\text { al }\end{array}$ & 8 & $\begin{array}{l}\text { Análise PCR de } \\
\text { biofilme do tubo de } \\
\text { pacientes extubados } \\
\text { em UTI, } 12-23 \text { dias. }\end{array}$ & $\begin{array}{l}70 \% \text { bactérias orais } \\
\text { (Streptoccocus, } \\
\text { Prevotella, Neisseria); } \\
6 \% \text { outras. Após } 23 \\
\text { dias, 95\% do total é de } \\
\text { Pseudomonas } \\
\text { aeruginosa }\end{array}$ & \\
\hline $\begin{array}{l}\text { Cairns et } \\
\text { al., } 2011\end{array}$ & $\begin{array}{l}\text { PLoS } \\
\text { ONE } \\
2011\end{array}$ & $\begin{array}{l}\text { Molecular } \\
\text { Analysis of } \\
\text { Microbial } \\
\text { Communities } \\
\text { in } \\
\text { Endotracheal } \\
\text { Tube Biofilms }\end{array}$ & $\begin{array}{l}\text { Caso- } \\
\text { controle }\end{array}$ & 24 & $\begin{array}{l}\text { Analisa o biofilme } \\
\text { microbiano de tubos } \\
\text { endotraqueais } \\
\text { através de PCR, } \\
\text { DGGE e cultura de } \\
\text { bactérias aeróbias. }\end{array}$ & 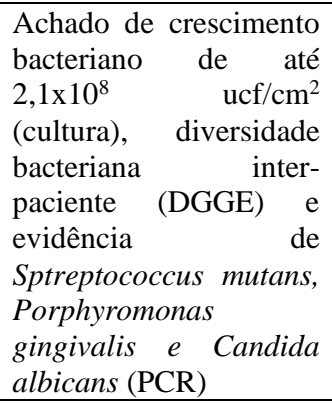 & \\
\hline $\begin{array}{l}\text { Porto et } \\
\text { al., } 2016\end{array}$ & $\begin{array}{l}\text { Eur J } \\
\text { Clin } \\
\text { Microbi } \\
\text { ol Infect } \\
\text { Dis }\end{array}$ & $\begin{array}{l}\text { Oral and } \\
\text { endotracheal } \\
\text { tubes } \\
\text { colonization } \\
\text { by periodontal } \\
\text { bactéria: a } \\
\text { case-control } \\
\text { ICU study }\end{array}$ & $\begin{array}{l}\text { Caso- } \\
\text { controle }\end{array}$ & 36 & $\begin{array}{l}\text { Correlação entre } A \text {. } \\
\text { actinomycetemcomit } \\
\text { ans }(A a) \text {, } \\
\text { Porphyromonas } \\
\text { gingivalis }(P g), e \\
\text { Tannerella Forsythia } \\
(T f) \text { em pacientes } \\
\text { dentados e edentados } \\
\text { intubados 5-7 dias. }\end{array}$ & $\begin{array}{l}\text { Sem correlação entre } \\
\text { parâmetros periodontais } \\
\text { dos dentados e o } \\
\text { biofilme do tubo e nem } \\
\text { entre o biofilme da } \\
\text { mucosa oral e o tubo. Já } \\
\text { para o grupo de } \\
\text { edêntulos, houve } \\
\text { correlação positiva } \\
\text { entre } A a, P g e T f \text { e o } \\
\text { biofilme do tubo. }\end{array}$ & \\
\hline $\begin{array}{l}\text { Sands et } \\
\text { al., } 2017\end{array}$ & $\begin{array}{l}\text { J Crit } \\
\text { Care }\end{array}$ & $\begin{array}{l}\text { Respiratory } \\
\text { pathogen } \\
\text { colonization } \\
\text { of dental } \\
\text { plaque, the } \\
\text { lower airways } \\
\text { and } \\
\text { endotracheal } \\
\text { tube biofilms } \\
\text { during } \\
\text { mechanical } \\
\text { ventilation }\end{array}$ & $\begin{array}{l}\text { Caso- } \\
\text { controle }\end{array}$ & 107 & $\begin{array}{l}\text { Analisa o biofilme } \\
\text { microbiano do } \\
\text { biofilme dental, do } \\
\text { tubo endotraqueal e } \\
\text { do trato respiratório } \\
\text { inferior durante } \\
\text { intubação e após } \\
\text { extubação. }\end{array}$ & $\begin{array}{l}\text { Alteração do biofilme } \\
\text { dental e do tubo após } \\
\text { início da ventilação } \\
\text { mecânica, } \\
\text { principalmente } S \text {. } \\
\text { aureus e P. } \\
\text { Biofilmeruginosa. } \\
\text { representa alto risco } \\
\text { para desenvolvimento } \\
\text { da PAV. }\end{array}$ & \\
\hline
\end{tabular}

Fonte: Autores.

\section{Discussão}

A pneumonia associada à ventilação é um risco de infecção importante para pacientes considerados críticos em ambiente de UTI hospitalar pois está diretamente relacionada com altas taxas de morbidades, mortalidades e custos 
hospitalares (Palmer Jr. et al., 2003). Uma das etiologias possíveis desta condição é a translocação bacteriana do meio bucal para os pulmões via tubo endotraqueal, devido a mudanças na dieta do indivíduo intubado, pela queda do fluxo salivar e por dificuldades da higienização oral, o que faz do tubo endotraqueal um artefato importante para ser analisado qualitativamente (Sands et al., 2017). A presença do tubo pode provocar lesões na mucosa traqueal, gerar a anulação do reflexo da tosse, acumular secreções no espaço subglótico e consequentemente favorecer a formação de biofilme e risco para desenvolvimento de infecções. Em simulação de uma ventilação mecânica in vitro com tubos orotraqueais, verificou-se que as bactérias se propagaram por pelo menos $15 \mathrm{~cm}$ de forma elíptica dentro do tubo (Ramirez, Ferrer \& Torres, 2007).

A origem do biofilme do tubo orotraqueal provavelmente está associada ao acúmulo de secreção do trato respiratório inferior, por aspiração inadequada, à secreção de fluído presente no trato respiratório superior e à inoculação de ar ativo proveniente do ventilador mecânico e, desta forma, considerando que os biofilmes são um reservatório importante de bactérias patogênicas, poderia haver favorecimento de desenvolvimento de infecções sistêmicas (Perkins, Woeltje \& Angenent, 2010). Foi relatado $70 \%$ dos pacientes com PAV apresentavam patógenos do tubo semelhantes aos dos pulmões e ainda demonstraram a grande complexidade dos constituintes do biofilme e dentre os microorganismos restritos de cavidade oral (Streptococus mutans e Porphyromonas gingivalis), onde o PCR demonstrou a presença destes em 9 de 20 pacientes. S. aureus e Pseudomonas aeruginosa, relacionadas diretamente à pneumonia infecciosa, correspondem a 20-24\% das PAV e também foram detectadas (Cairns et al., 2011). Demonstrou-se que 70\% das bactérias presentes no biofilme do tubo são orais (Streptoccocus, Prevotella, Neisseria), 6\% de outras origens e que após 23 dias, 95\% do total é de Pseudomonas aeruginosa, espécie bacteriana de vias aéreas superiores mais comum e maior responsável por pneumonias (Perkins, Woeltje \& Angenent, 2010). Em outro estudo, foram reportados achados de Pseudomonas spp. e Enterobacteriaceae no biofilme do tubo endotraqueal (Ramirez, Ferrer \& Torres, 2007). Em análise de reação em cadeia de polimerase -PCR, a presença de Streptococcus é a que se encontra em maior abundância. Isso se deve ao fato de que é a espécie bacteriana mais comum em cavidade oral e nasofaringe, justamente por onde os tubos são inseridos. Além disso, esta espécie tem muita habilidade de fazer coagregação com outras espécies bacterianas e formar biofilmes mais complexos (Palmer Jr. et al., 2003). Foi relatado que quase um terço das amostras de biofilme dental e no biofilme do tubo orotraqueal tiveram colonização de Staphylococcus aureus e Pseudomonas aeruginosa, responsáveis por 50\% dos casos de PAV (Sands et al., 2017). Patógenos como Pseudomonas aeruginosa e Staphylococcus aureus encontram-se com mais frequência no biofilme dental em pacientes de UTI, o que viabiliza a maior chance de adesão desses ao biofilme do tubo, embora a avaliação do biofilme dental antes da intubação demonstrou que havia presença de pelo menos S. aureus (48\% eram negativos antes da intubação) ou P. aeruginosa (78\% eram negativos antes da intubação) durante ventilação mecânica.

Considerando ainda que pacientes com periodontite carregam patógenos importantes da doença periodontal, é justo e compreensível considerar a presença destes microorganismos também no biofilme do tubo orotraqueal (Gomes-Filho et al., 2014). Em um trabalho (Porto et al., 2016), analisaram-se índices clínicos periodontais em 18 pacientes dentados e foram correlacionados com amostras microbianas em biofilme do tubo orotraqueal e em mucosa oral deste mesmo grupo e de um outro grupo com 18 pacientes edêntulos. Foi analisada a carga bacteriana total de Aggregatibacter actinomycetemcomitans (Aa), Porphyromonas gingivalis (Pg), e Tannerella forsythia (Tf) em exame de PCR. Estatisticamente não houve correlação entre parâmetros periodontais dos dentados e o biofilme do tubo e nem entre o biofilme da mucosa oral e o tubo. Já para o grupo de edêntulos, houve correlação positiva entre Aa, Pg e Tf e o biofilme do tubo. Foi demonstrada pouca influência da presença de dentes no nível de bactérias do biofilme do tubo. Desta forma consideraram que a boca como um todo seria a fonte de contaminação bacteriana ao biofilme do tubo. Ainda, considerando que o A. actinomycetemcomitans, Porphyromonas gingivalis, e Tannerella forsythia também são encontrados na mucosa de edentados torna-se oportuno e fundamental o manejo eficiente no controle de biofilme destes pacientes tão bem quanto aquele realizado em pacientes dentados (Porto et al., 2016). 
Um estudo (Perkins, Woeltje \& Angenent, 2010) demonstrou presença de biofilme no tubo orotraqueal após 24 horas da intubação e que $70 \%$ das bactérias encontradas no tubo eram típicas da cavidade bucal, como Streptococcus spp, Actinomyces spp, Veillonella spp. A presença de bactérias orais no tubo não só facilita a adesão de bactérias do trato respiratório, como promovem a coagregação de diferentes espécies bacterianas, aumentam o poder de virulência de certas bactérias e aumentam a tolerância a antibióticos. Candida albicans mostra uma sinergia com S. aureus e P. aeruginosa; portanto, a colonização do trato respiratório com $C$. albicans está associada com o aumento de $P$. aeruginosa - pois este pode fornecer nutrientes a esta bactéria - e consequentemente o tratamento com antifúngicos eficientes gerariam uma diminuição de P. aeruginosa. Como bactérias da cavidade oral podem estar relacionadas com o trato respiratório inferior, a relação da microbiota da boca pode ter impacto nas infecções respiratórias.

No caso das PAV, bactérias da boca podem colonizar o biofilme dentário e o biofilme do tubo endotraqueal ou podem ainda diretamente causar PAV (Brennan et al., 2004). Em um estudo, os autores conferem que a relação causal entre o biofilme e PAV não está claramente estabelecida (Ramirez, Ferrer \& Torres, 2007) e que o estudo sugere que a administração de antibióticos ao paciente já traz mudanças na composição do biofilme, assim como, a higienização mecânica reduz e até elimina o biofilme. $\mathrm{O}$ efeito deste biofilme na incidência da PAV ainda não estaria concluído, atribuindo que o biofilme seja muito mais um reservatório de bactérias, em especial para Pseudomonas spp. e Enterobacteriaceae do que estas bactérias pudessem ser efeito causal para PAV.

Uma revisão sistemática conclui-se que o biofilme oral é colonizado por patógenos que causam infecção pulmonar, associado a uma pobre higienização de boca e que podem estar relacionados com a PAV (Scannapieco \& Mylotte, 1996). Considera-se que o paciente com estada na UTI tem um risco maior de adquirirem patógenos mais virulentos quando comparados a pacientes não hospitalizados e sadios e soma-se ainda o fato de que o foco no ambiente hospitalar é a manutenção da vida do paciente, tendo esta então como prioridade e que um protocolo padronizado de assistência no leito de UTI minimizaria riscos de desenvolvimento de outras comorbidades sistêmicas (Cutler \& Davis, 2005). Vários mecanismos poderiam explicar como estas bactérias participam da patogênese das infecções respiratórias; dentre estas, citam-se (1) inalação de aerossol, (2) aspiração do conteúdo da orofaringe, (3) contaminação por via hematogênica e (4) translocação bacteriana. Pacientes intubados passam a ser, então, um foco de estudo (Scannapieco \& Mylotte, 1996).

\section{Conclusão}

No presente trabalho fica evidente que o tubo endotraqueal é colonizado por microorganismos orais através da adesão bacteriana, principalmente Strepcococcus spp. e que à medida que ocorre a maturação deste biofilme, haverá um processo de coagregação e simbiose com microorganismos mais virulentos capazes de promoverem processos infecciosos nos pulmões.

Desta forma, é necessário o entendimento do mecanismo de formação, maturação e patogenicidade do biofilme dental e orotraqueal, visto que mudanças na microbiota da cavidade bucal (principalmente de $S$. aureus e $P$. aeruginosa) em pacientes sob ventilação mecânica são fatores de risco para PAV e que, portanto, manter a higienização oral durante a ventilação mecânica reduz o reservatório de patógenos respiratórios dentro do biofilme dentário e consequentemente do tubo endotraqueal.

\section{Referências}

Aas, J. et al. (2005) Defining the Normal Bacterial Flora of the Oral Cavity. Journal of Clinical Microbiology, 43(11), 5721-5732.

Barros, B. F. M. et al. (2021). Use of low power laser in the treatment of oral injuries in patients with neurological diseases: Case report. Research, Society and Development, 10(6), e47110616083. https://doi.org/10.33448/rsd-v10i6.16083 
Research, Society and Development, v. 10, n. 7, e45010714661, 2021

(CC BY 4.0) | ISSN 2525-3409 | DOI: http://dx.doi.org/10.33448/rsd-v10i7.14661

Beraldo, C.C. \& Andrade, D. (2008) Higiene bucal com clorexidina na prevenção de pneumonia associada à ventilação mecânica. Jornal Brasileiro de Pneumologia. 34(9), 707-714.

Brennan, M. T. et al. (2004) The role of oral microbial colonization in ventilator-associated pneumonia. Oral Surgery Oral Medicine Oral Pathology Oral Radiology and Endodontics, 98: 665-672.

Cairns, S. et al. (2011) Molecular Analysis of Microbial Communities in Endotracheal Tube Biofilms. PLoS ONE, 6(3), e14759.

Cutler, C. \& Davis, N. (2005) Improving oral care in patients receiving mechanical ventilation. American Journal of Critical Care, $14,389-394$.

Dewhirst, F. E. et al. (2010) The human oral microbiome. Journal of Bacteriology, 192(19), 5002-5017.

Gomes-Filho, I. S. et al. (2014) Influence of periodontitis in the development of nosocomial pneumonia: a case control study. Journal of Periodontology, $85(5), 82-90$.

Palmer Jr., et al. (2003) Coaggregation mediated interactions of streptococci and actinomyces detected in initial human dental plaque. Journal of Bacteriology, 185, 3400-3409.

Par, M., Badovinac, A. \& Plancak, D. (2014) Oral hygiene is an important factor for prevention of ventilator-associated pneumonia. Acta Clinica Croatica, 53(1), $72-78$.

Perkins, S. D., Woeltje, K. F. \& Angenent, L. T. (2010) Endotracheal tube biofilm inoculation of oral flora and subsequent colonization of opportunistic pathogens. International Journal of Medical Microbiology, 300, 503-511.

Porto, N. A. et al. (2016) Oral and endotracheal tubes colonization by periodontal bacteria: a case-control ICU study. European Journal of Clinical Microbiololy \& Infectious Diseases, 35, 343-351.

Ramirez, P., Ferrer, M. \& Torres, A. (2007) Prevention measures for ventilator-associated pneumonia: a new focus on the endotracheal tube. Current Opinion in Infectious Diseases, 20, 190-197.

Safdar, N., Crnich. C. \& Maki, D. (2005) The Pathogenesis of Ventilator associated Pneumonia: its relevance to developing effective strategies for prevention. Respiratory Care, 50(6), 725-739.

Sands, K. M. et al. (2017) Respiratory pathogen colonization of dental plaque, the lower airways and endotracheal tube biofilms during mechanical ventilation. Journal of Critical Care, 37, 30-37.

Scannapieco, F. A., Bush, R. B. \& Paju, S. (2003) Associations between periodontal disease and risk for nosocomial bacterial pneumonia and chronic obstructive pulmonary disease. A systematic review. Annal of Periodontology, 8(1), 54-69.

Scannapieco, F. A. \& Mylotte, J. M. (1996) Relationships between periodontal disease and bacterial pneumonia. Journal of Periodontology, 67(10), 11141122 